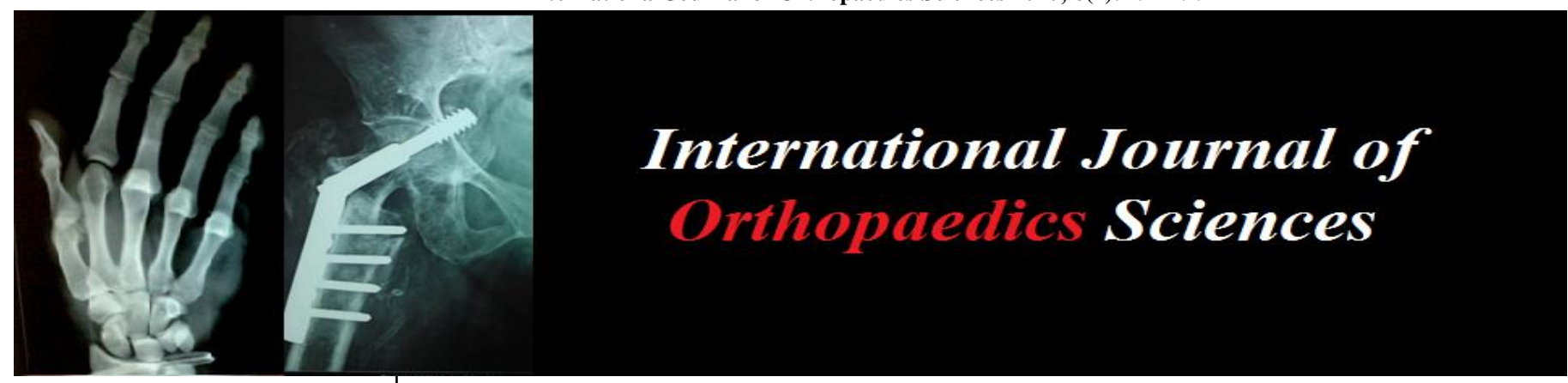

E-ISSN: 2395-1958

P-ISSN: 2706-6630

IJOS 2020; 6(2): 191-195

(C) 2020 IJOS

www.orthopaper.com

Received: 20-01-2020

Accepted: 24-02-2020

Dr. Rajesh Kumar Sharma Senior Resident, Department of Orthopaedics, SMS Medical College, Jaipur, Rajasthan, India

Dr. Arun Kumar Sharma

Assistant Professor, Department of Orthopaedics, SMS Medical College, Jaipur, Rajasthan, India

Dr. Vishal Sekhawat

Assistant Professor, Department of Orthopaedics, SMS Medical

College, Jaipur, Rajasthan, India

Dr. Avtar Singh Balawat Assistant Professor, Department of Orthopaedics, SMS Medical

College, Jaipur, Rajasthan, India

Corresponding Author: Dr. Rajesh Kumar Sharma Senior Resident, Department of Orthopaedics, SMS Medical College, Jaipur, Rajasthan, India

\section{Results of surgical management of displaced or complex proximal humeral fractures with proximal Humerus internal locking system: A prospective study of 55 cases}

\author{
Dr. Rajesh Kumar Sharma, Dr. Arun Kumar Sharma, Dr. Vishal \\ Sekhawat and Dr. Avtar Singh Balawat
}

DOI: https://doi.org/10.22271/ortho.2020.v6.i2c.2036

\section{Abstract}

Background: The optimal treatment of proximal humeral fractures remains always challenging and controversial. The purpose of this prospective study was to evaluate the functional outcome of proximal humerus internal locking system (PHILOS) plate fixation for displaced or complex proximal humeral fractures and to establish the influencing factors of an unfavourable outcome.

Materials and Methods: After obtaining approval from institutional ethics committee, 55 patients with the displaced proximal humeral fractures were managed by open reduction and PHILOS plate fixation through delto-pectoral approach and as per standard protocol. The results of follow-ups were analysed radiologically and clinically, using the "Constant and Murley scoring system" at once in a month for first three months, once in three months for next six months and once in six months thereafter upto 2 years post-operatively.

Results: In the present study, out of 55 patients, clinical results were excellent in $50.9 \%$, good in $21.8 \%$, fair in $16.4 \%$ and poor in $10.9 \%$ patients. Radiological union was achieved in all patients, including two cases of mal-union and one case of delayed union. Post- traumatic frozen shoulder ( 7 cases), secondary arthritis ( 5 cases), secondary screw penetration ( 3 cases), and AVN humeral head ( 3 cases) were the main complications observed in this study during 2 years of follow-ups, which were treated accordingly.

Conclusion: Pre-contoured PHILOS plate preserves shape of humeral head, provides angular stability, facilitates to restore the medial column and prevent secondary varus collapse in severe comminuted and osteoporotic proximal humeral fractures. With proper patient selection, PHILOS plate provides favourable clinical and radiological outcome with acceptable complication rates.

Keywords: PHILOS, delto-pectoral approach, Constant and Murley scoring system, frozen shoulder

\section{Introduction}

Proximal humeral fractures are the third most common fractures after hip fractures and distal end radial fractures in patients who are older than sixty-five years of age ${ }^{[1]}$. These fractures have bimodal age distribution with $4-5 \%$ incidence rate ${ }^{[2]}$. Proximal humeral fractures usually caused by low energy injury in older patients, while in young adults these fractures are usually due to high energy trauma and are associated with severe comminutions [3, 4]. Proximal humeral fractures are classified as two part, three-part and four-part fractures and those with dislocation of head of humerus, according to Neer's classification system ${ }^{[5]}$.

The treatment of choice is always controversial here. Previously published literature suggest that there is no universally accepted standard form of treatment for proximal humeral fractures. Majority of undisplaced fractures can be treated conservatively with a sling immobilization and physical therapy. Although, approximately $20 \%$ of displaced proximal humeral fractures have surgical indication ${ }^{[3,4]}$.

The type of fixation used depends on age and activity level of patient, quality of bone, type of fracture and the surgeon's operative skills. Trans-osseous suture fixation, closed reduction and percutaneous fixation with K-wires, open reduction and internal fixation with conventional plates, locking plate fixation and hemiarthroplasty, are the surgical treatment modalities which 
have shown to have mixed functional outcomes ${ }^{[4,6]}$.

The influencing factors to functional outcome are fracture reduction, implant choice, quality of fracture reduction and fixation, and early post-op mobilization. Complications like stiffness of shoulder joint, avascular necrosis of humeral head and secondary osteoarthritis are usually related to the severity of the fracture. Complications like malunion, varus collapse, implant failure and non-union are usually related to the treatment option selected ${ }^{[7,8,9]}$.

For open reduction and internal fixation of these fractures, a recently developed operative system is PHILOS (proximal humerus internal locking system). It's a fixed angled device with pre-contoured locking compression plate which maintains angular stability under load, reduces risk of malreduction, preserves viability and shape of humeral head, promotes early mobilization, and helps in restoration of range of motion of shoulder joint ${ }^{[10,11]}$.

The purpose of this study was to assess the functional outcome and surgical complications in displaced or complex proximal humeral fractures treated with the proximal humerus internal locking system (PHILOS) locking plates using Constant and Murley scoring system ${ }^{[12]}$.

\section{Materials and Methods}

This study was conducted during the years 2016 to 2019 in the department of Orthopaedics, SMS Medical College, Jaipur (Rajasthan). Prior to initiation of this study, approval of local ethical committee was received. We designed a prospective study with sample size of 55 patients with proximal humeral fractures, who met with inclusion criteria, underwent PHILOS plate fixation. We obtained the written informed consent from every patient involved in the study.

Inclusion Criteria: The inclusion criteria were skeletally matured patients with closed -two part, three part and four part fractures of proximal humerus with a displacement of $>1$ $\mathrm{cm}$, varus angulation of $>45$ degree, and had readiness to take part in the study, were included.

Exclusion Criteria: Pediatric patients, undisplaced fractures, valgus impacted fractures, open fractures, severely comminuted fractures, fractures with nerve injury, and pathological fractures were excluded from this study.

All the mandatory preoperative investigations were done. To understand the morphology of fracture and to classify it, an adequate radiological assessment was carried out before each surgery. In this study, all the fractures were classified as per the Neer's classification system ${ }^{[5]}$.

\subsection{Surgical Technique}

All surgeries were performed by the same surgical team under general anaesthesia combined with a regional block anaesthesia. A beach chair position and the delto-pectoral approach was used in all patients. About $8-10 \mathrm{~cm}$ long incision, started from corocoid process, was given along the deltopectoral groove. The internervous plane was identified between deltoid and the pectoralis major muscle and these muscles were separated. Depending upon the surgical exposure, the cephalic vein was retracted laterally or medially. Further incision was made in the line of fibers of subscapularis muscle, with external rotation of arm to make its fibers taut. For later meticulous repair of rotator cuff muscles, tag sutures were taken.
The fracture fragments were identified, and reduced properly. A 'PHILOS' plate of appropriate size, positioned laterally and provisionally fixed to the humeral head with $\mathrm{K}$-wires at least $1 \mathrm{~cm}$ distal to the proximal end of the greater tubercle to prevent subacromial impingement. The plate was applied to the humeral head with appropriate size proximal locking screws before the distal screws were inserted into the humeral shaft. Finally, the stability of fracture fixation was tested. The entire method was supervised under image intensifier control. At the end of procedure, a suction drain was inserted and meticulous closure was done in layers. The arm pouch sling was applied and active finger movements were advised.

Post-operatively intravenous antibiotics were given for 48 hours and wound dressing was checked on second postoperative day. Routine post-operative X-rays were done before discharge.

\subsection{Post-operative follow-up}

After the surgery, we taught standardized rehabilitation protocol to each patient involved in this study. From the 2nd post-operative day, pendular movements of shoulder joint were started. After $10^{\text {th }}$ post-op days, active assisted exercises were started, while pure active exercises were started at four weeks post-operatively.

Follow-ups were done regularly, once in a month for first three months, once in three months for next six months and once in six months thereafter upto 2 years post-operatively. At each follow-up, clinical assessment of shoulder joint was done in the form of pain, activities of daily living and range of movements, using Constant and Murley scoring system ${ }^{[12]}$.

Radiological signs of healing at fracture site were assessed at three and six months follow-up radiographs in anteroposterior and axial views. Complications like secondary screw penetration, secondary arthritis, avascular necrosis, and implant failure were also assessed.

\subsection{Statistical analysis}

Statistical analysis was performed using SPSS software version 16.0 and MS Excel 2013. In this study, qualitative variables were demonstrated in proportion and quantitative variables were presented by mean and standard deviation.

\section{Results}

In this study, fifty-five eligible patients were operated during the study period from the years 2016 to 2019. Out of 55 patients, 21 were male and 34 were female, with mean age of 56.63 years (range $24-78$ ). The mode of injury in 20 patients was motor vehicle collision, in 29 patients was domestic fall, and in rest 6 patients was fall from staircase. The average duration of follow-ups, was 18.5 (range 9-27) months. [Table 1]

In this study, out of 55 patients, 19 had two- part fracture, 28 had three- part fracture and remaining 8 patients had fourpart fracture, according to the Neer's classification system ${ }^{5}$. All fractures included in our study, were of closed types. At three months follow-up, 54 fractures, out of 55, united clinically and radiologically. One patient with three-part fracture had associated shoulder dislocation in which delayed union occurred at the end of 24 weeks.

The results at final follow-up were excellent in 28 patients, good in 12 patients, fair in nine patients and poor in six patients according to the Constant \& Murley scoring system ${ }^{[12]}$. [Table 2, Figure 1-7]. 
Table 1: Showing demographic variables of the study

\begin{tabular}{|c|c|c|}
\hline \multicolumn{2}{|c|}{ Demographic variables } & Features \\
\hline \multicolumn{2}{|c|}{ Study design } & Prospective study \\
\hline \multicolumn{2}{|c|}{ Study period } & $2016-2019$ \\
\hline \multicolumn{2}{|c|}{ Total number of the patients } & 55 \\
\hline \multicolumn{2}{|c|}{ Mean age (range) in years } & $56.63(24-78)$ \\
\hline \multirow{2}{*}{\multicolumn{2}{|c|}{$\begin{array}{c}\text { Male: Female } \\
\text { Average duration of follow-ups (in months) }\end{array}$}} & $21: 34$ \\
\hline \multirow{2}{*}{\multicolumn{2}{|c|}{\begin{tabular}{l}
\multicolumn{2}{|c}{ Average duration of follow-ups (in months) } \\
Motor vehicle collision
\end{tabular}}} & $18.5(9-27)$ \\
\hline & & 20 \\
\hline \multirow[t]{2}{*}{ Mode of injury } & Domestic fall & 29 \\
\hline & Fall from staircase & 6 \\
\hline
\end{tabular}

Table 2: Showing the functional outcome of the study

\begin{tabular}{|c|c|c|c|c|}
\hline $\begin{array}{c}\text { Results } \\
\text { (according to Constant \& } \\
\text { Murley scoring system) }[\mathbf{1 2}]\end{array}$ & $\begin{array}{c}\text { 2- part } \\
\text { fracture } \\
(\mathbf{n = 1 9})\end{array}$ & $\begin{array}{c}\text { 3- part } \\
\text { fracture } \\
(\mathbf{n = 2 8})\end{array}$ & $\begin{array}{c}\text { 4- part } \\
\text { fracture } \\
(\mathbf{n = 8})\end{array}$ & $\begin{array}{c}\text { Total Number of patients } \\
\text { \& Percentage (n=55) }\end{array}$ \\
\hline Excellent & 13 & 15 & 0 & $28(50.9 \%)$ \\
\hline Good & 4 & 6 & 2 & $12(21.8 \%)$ \\
\hline Fair & 2 & 6 & 1 & $9(16.4 \%)$ \\
\hline Poor & 0 & 1 & 5 & $6(10.9 \%)$ \\
\hline
\end{tabular}

\section{According to Constant \& Murley} scoring system $(\mathrm{n}=55)$

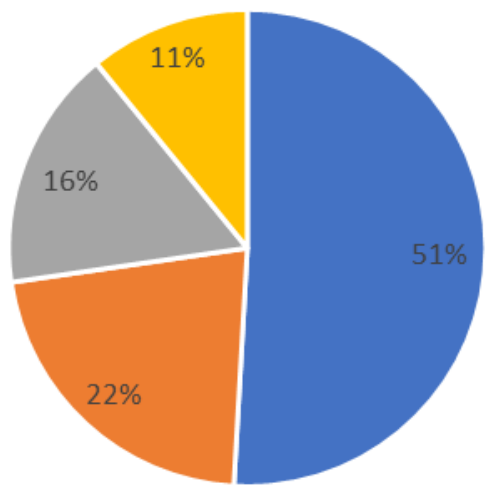

- Excellent " Good a Fair a Poor
- 2- part fractures $(\mathrm{n}=19)$ - 3-part fractures $(\mathrm{n}=28)$

4- part fractures $(\mathrm{n}=8)$

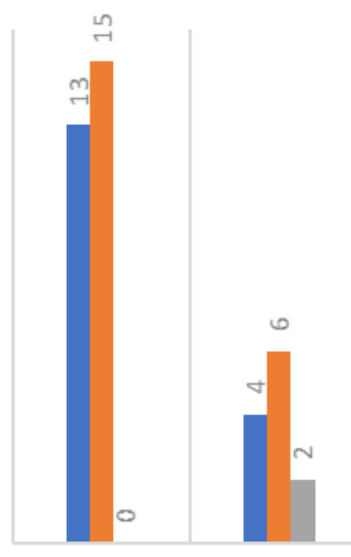

EXCELLENT

GOOD

Fig 1-2: Showing functional outcome of the study according to Constant $\&$ Murley scoring system ${ }^{12}$ and Neer's fracture classification ${ }^{[5]}$.

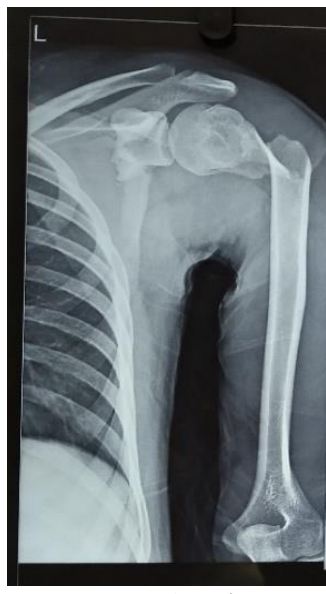

Pre-op AP view

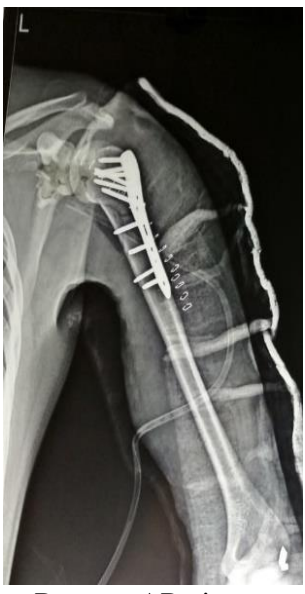

Post-op AP view

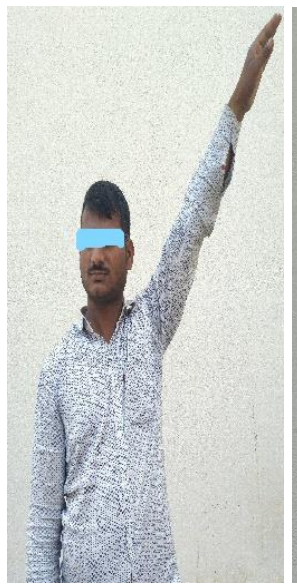

Lateral elevation

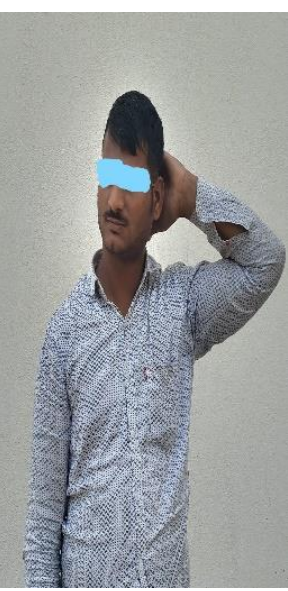

External rotation

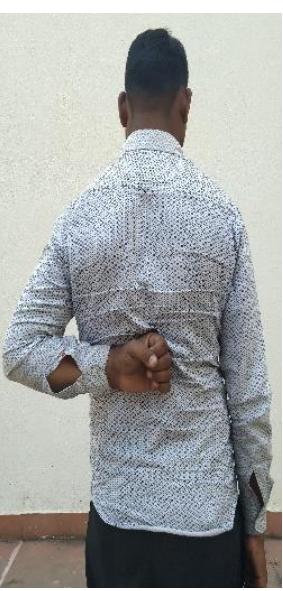

Internal rotation

Fig 3-7: Evaluation of radiological and functional outcome of proximal humeral fracture, treated with PHILOS plate fixation at 9 months follow-up.

\subsection{Complications of the study}

We encountered some complications at the follow-ups of the patients. The complications of our study, are expressed here in tabulated form. [Table 3] 
Table 3: Showing the complications of the study.

\begin{tabular}{|c|c|}
\hline Complications & $\begin{array}{c}\text { oumber of patients \& Percentage } \\
(\mathbf{n = 5 5})\end{array}$ \\
\hline Superficial surgical site infection & $2(3.6 \%)$ \\
\hline Primary screw penetration & $2(3.6 \%)$ \\
\hline Secondary screw penetration & $3(5.4 \%)$ \\
\hline Subacromian impingement & $2(3.6 \%)$ \\
\hline Post- traumatic frozen shoulder & $7(12.7 \%)$ \\
\hline Secondary varus collapse & $1(1.8 \%)$ \\
\hline Implant failure & $1(1.8 \%)$ \\
\hline Mal-union & $2(3.6 \%)$ \\
\hline AVN* humeral head & $3(5.4 \%)$ \\
\hline Secondary arthritis & $5(9.1 \%)$ \\
\hline Delayed-union & $1(1.8 \%)$ \\
\hline
\end{tabular}

*AVN: Avascular Necrosis.

\section{Discussion}

Proximal humeral internal locking system (PHILOS) is an anatomically contoured, fixed-angle construct that merges locking screw technique with conventional plating technology. It provides angular stability, perticularly useful in osteopenic bone or multifragmentary fractures of proximal humerus where purchase of traditional screw is compromised. In the present study, the age of patients with proximal humeral fractures ranged between $24-78$ years with mean age of 56.63 years. This mean age in our study was probably due to higher incidence of this fracture in osteoporotic bone, as incidence of osteoporosis increases with age.

Females were affected much more commonly than males. In present study 34 patients were female and 21 patients were male. Predominant female involvement is probably due high incidence of osteoporosis in female patient. These findings are comparable to the study results of Handschin AE, et al. [13]

In our study, Neer's classification system for proximal humeral fractures, was used to allow accurate anatomical description, guide treatment and allow an estimation of prognosis. In out of 55 cases of our study, there were 19 cases of 2-part fracture, 28 cases were of 3-part fracture and 8 cases were of 4-part fracture. In the study of Geiger EV et al. ${ }^{[14]}$, out of 28 cases there were 8 cases of 2-part fracture, 12 cases of type 3-part fracture and 8 cases of type 4-part fracture.

In the present study, the results were expressed according to the Constant \& Murley scoring system ${ }^{[12]}$, in which scores of $<60$ were graded as poor, 60 to 74 as fair, 75 to 89 as good, and scores 90 and more were graded as excellent. Out of a total of 55 cases of our study, results were as excellent in $50.9 \%$ cases, good in $21.8 \%$ cases, fair in $16.4 \%$ cases and poor in $10.9 \%$ cases. The mean Constant \& Murley score in this study was 76 . Our results were comparable with results of previous studies, mentioned in the literature ${ }^{[10,15,16]}$.

In the present study, out of 55 cases, two (3.6\%) patients had post-operative superficial surgical site infection, which were successfully treated with proper dressings and oral antibiotics. There was no long term bad effect on fracture healing or rehabilitation of these patients due to this superficial infection. We did not observe any case with deep infection.

We encountered two (3.6\%) cases with one primary screw penetration into shoulder joint, which was remove after one month under image intensifier with better outcome in both cases. We also observed three $(5.4 \%)$ cases with secondary screw penetration in their further follow-ups, which were later revised with hemiarthroplasty. It could be due to severely comminuted fracture pattern and severe osteoporosis in elderly patients. Two (3.6\%) cases were identified with subacromian impingement due to slight higher placement of
PHILOS plates. These patients were managed conservately with satisfactory functional outcome. In the study of Geiger EV et al. ${ }^{[14]}$, out of 28 cases, 6 cases of subachromial impingement and one case of loosening of locking head screw were recorded.

Post-traumatic frozen shoulder was observed in seven patients $(12.7 \%)$. We started adequate physiotherapy and rehabilitation as earliest. Satisfactory pain relief with functional range of motion was achieved in all these patients. There was one $(1.8 \%)$ case of secondary varus collapse with limited range of movements. We also observed one (1.8\%) patient with implant failure, for which implant removal was done at his six months follow-up. In later follow-ups, fracture mal-union was noticed in both the patients (3.6\%).

In the present study, radiological union seen between 10-14 weeks in most of the cases. Delayed union was observed in one case $(1.8 \%)$, in which union occurred at the end of 24 weeks of follow-up. In the study of Kilic B et al. ${ }^{[15]}$ the average time for fracture healing was 10 weeks, and in one case union was observed at 16 weeks.

In this study, we noted avascular necrosis of humeral head in three $(5.4 \%)$ patients, for which these patients have to go replacement arthoplasty at later stage. In the study of Geiger EV et al. ${ }^{[14]}$, out of 28 cases, 2 cases of avascular necrosis were recorded. Similarly, avascular necrosis incidence varies from $0 \%$ to $68 \%$ in the study of Acklin YP et al. ${ }^{[17]}$.

Other complications recorded were secondary arthritis in five $(9.1 \%)$ patients, and delayed union in one $(1.8 \%)$ patient. However, all these patients had good functional outcome. They refused for any additional surgery and managed with non-operative care. Similar results were observed in the study of Martinez AA et al. ${ }^{[18]}$.

\subsection{Limitations of the study}

One of the major limitation of our study was small sample size. The small sample size has an influence on the evaluation of outcomes, as it can overrate the results. Furthermore, the study includes solitary method of fracture fixation with PHILOS plate only while other various fixation methods could have also been used for comparison and to conclude more significant results.

\section{Conclusion}

Proximal humerus internal locking system has wonderful outcome in comminuted fractures of proximal humerus with severe osteoporosis. PHILOS plate provides favourable and stable fracture fixation with acceptable complication rates. It helps to promote early mobilization, better rehabilitation and maintains the functional activity level of the patient. During fracture fixation, anatomic reduction and restoration of medial column are the pivotal factors to prevent secondary varus collapse. With proper patient selection, these goals can be nearly achieved by pre-contoured PHILOS plate fixation, as it provides angular stability, and preserves shape of humeral head.

\section{Acknowledgement: None \\ 7. Declarations}

Funding: None

Conflict of interest: None.

Ethical approval: This study was approved by the institutional ethics committee.

\section{References}

1. Court-Brown CM, Garg A, McQueen MM. The 
epidemiology of proximal humeral fractures. Acta Orthop Scand. 2001; 72(4):365-71.

2. Neer CS II, Rockwood CA. Fractures and dislocations of the shoulder, in Rockwood and Green: Fractures in adults, Philadelphia, PA, Lippincott, 1984, 675-721.

3. Iannotti JP, Ramsey ML, Williams GR, Warner JJP. Nonprosthetic management of proximal humeral fractures. J Bone Joint Surg Am. 2003; 85:1578-93.

4. Nho SJ, Brophy RH, Barker JU, Cornell CN, MacGillivray JD. Management of proximal humerus fracture based on current literature. J Bone Joint Surg Am. 2007; 89(3):44-58.

5. Neer CS. Displaced proximal humeral fractures. I. Classification and evaluation. J Bone Joint Surg Am [Internet]. 1970 Sep [cited. 2018; 52(6):1077-89. Available from: http://www.ncbi.nlm.nih.gov/pubmed/5455339

6. Michael W, Andre F, Robert F. Locked plating: biomechanics and biology and locked plating: clinical indications. Techniques in Orthopaedics. 2007; 22(4):209- 18.

7. Smith AM, Mardones RM, Sperling JW, Cofield RH. Early complications of operatively treated proximal humeral fractures. J Shoulder Elbow Surg. 2007; 16(1):14-24.

8. Tolat AR, Amis A, Crofton S, Sinha J. Failure of humeral fracture fixation plate in a young patient using the Philos system: case report. J Shoulder Elbow Surg. 2006; 15(6):44-7.

9. Voigt C, Woltmann A, Partenheimer A, Lill $\mathrm{H}$. Management of complications after angularly stable locking proximal humerus plate fixation. Chirurg. 2007; 78(1):40-6.

10. Moonot P, Ashwood N, Hamlet M. Early results for treatment of three- and fourpart fractures of the proximal humerus using the PHILOS plate system. J Bone Joint Surg Br. 2007; 89(9):1206-09.

11. Bigliani LU. Fractures of the proximal humerus. In: Rockwood CA, Matsen FA, eds. The Shoulder. Philadelphia: W. B. Saunders, 1990, 278-334.

12. Constant CR, Murley AH. A clinical method of functional assessment of the shoulder. Clin Orthop Relat Res. 1987; 214:160-4.

13. Handschin AE, Cardell M, Contaldo C, Trentz O, Wanner GA. Functional results of angular-stable plate fixation in displaced proximal humeral fractures. Injury. 2008; 39(3):306-13.

14. Geiger EV, Maier M, Kelm A, Wutzler S, Seebach C, Marzi I. Functional outcome and complications following PHILOS plate fixation in proximal humeral fractures Acta Orthop Traumatol Turc. 2010; 44(1):1-6.

15. Kilic B, Uysal M, Cinar BM, Ozkoc G, Demirors H, Akpinar S. et al. Early results of treatment of proximal humerus fractures with the PHILOS locking Plate Acta Orthop Traumatol Turc. 2008; 42(3):149-53.

16. Björkenheim JM, Pajarinen J, Savolainen V. Internal fixation of proximal humeral fractures with a locking compression plate: a retrospective evaluation of 72 patients followed for a minimum of 1 year. Acta Orthop Scand. 2004; 75(6):741-5.

17. Acklin YP, Stoffel K, Sommer C. A prospective analysis of the functional and radiological outcomes of minimally invasive plating in proximal humerus fractures. Injury [Internet]. 2013 Apr [cited. 2018; 44(4):456-60. Available http://www.ncbi.nlm.nih.gov/pubmed/23043975.

18. Martinez AA, Cuenca J, Herrera A. PHILOS plate fixation for proximal humeral fractures J Orthop Surg (Hong Kong). 2009; 17(1):10-4. 